\title{
DISTRIBUTION OF THE MOST COMMON GENETIC VARIANTS ASSOCIATED WITH A VARIABLE DRUG RESPONSE IN THE POPULATION OF THE REPUBLIC OF MACEDONIA
}

\author{
Kapedanovska Nestorovska A ${ }^{1}$, Jakovski $\mathrm{K}^{2}$, Naumovska $Z^{1}$, Hiljadnikova Bajro $\mathrm{M}^{1}$, \\ Sterjev Z ${ }^{1}$, Eftimov A ${ }^{1}$, Matevska Geskovska $\mathrm{N}^{1}$, Suturkova L ${ }^{1}$, Dimitrovski $\mathrm{K}^{3}$, \\ Labacevski ${ }^{3}$, Dimovski AJ ${ }^{1, *}$
}

*Corresponding Author: Aleksandar J. Dimovski, MD., Ph.D., Center for Biomolecular and Pharmaceutical Analysis, Faculty of Pharmacy, University Ss Cyril and Methodius, Mother Theresa 47, Skopje 1000, Republic of Macedonia. Tel: +389-2-3217-580; +389-2-3119-694. Fax: +389-2-3290-830; +389-2-3123 054. E-mail: adimovski@ff.ukim.edu.mk

\begin{abstract}
Genetic variation in the regulation, expression and activity of genes coding for Phase I, Phase II drug metabolizing enzymes (DMEs) and drug targets, can be defining factors for the variability in both the effectiveness and occurrence of drug therapy side effects. Information regarding the geographic structure and multi-ethnic distribution of clinically relevant genetic variations is becoming increasingly useful for improving drug therapy and explaining inter-individual and inter-ethnic differences in drug response.

This study summarizes our current knowledge about the frequency distribution of the most common allelic variants in three broad gene categories: the Phase I oxidation-cytochrome P450 (CYP450) family (CYP2C9, CYP2C19, CYP3A5, CYP2D6); the Phase II conjugation (GSTT1, SULT1A1; UGT1A1) and drug target (TYMS-TSER, MTHFR and VKORC1) in the population of the Republic of Macedonia and compares the information obtained with data published for other indigenous European populations.
\end{abstract}

Supplementary material avalible online at:

http://bjmg.edu.mk/tekstovi/supplementary/1_MS39714

Dimovski_SUPPLEMENTARY_MATERIAL_.pdf

${ }^{1}$ Center for Biomolecular and Pharmaceutical Analysis, Faculty of Pharmacy, University Ss Cyril and Methodius, Skopje 1000, Republic of Macedonia

2 Department of Preclinical and Clinical Pharmacology and Toxicology, Faculty of Medicine, University Ss Cyril and Methodius, Skopje 1000, Republic of Macedonia

${ }^{3}$ Republic Institute for Transfusiology, Faculty of Medicine, University Ss Cyril and Methodius, Skopje 1000, Republic of Macedonia
Our findings define the population of the Republic of Macedonia as an ethnic group with a highly polymorphic genetic profile. These results add to the evidence regarding the distribution of clinically important variant alleles in DME and drug target genes in populations of European ancestry.

Keywords: Drug metabolizing enzymes (DMEs); Drug target; Allelic variants; Republic of Macedonia

\section{INTRODUCTION}

Patient-to-patient variability in drug response is one of the major problems in clinical practice and drug development. Aberrant drug responses, such as a lack of therapeutic effect and adverse drug reactions, have been associated with severe medical and economic consequences. The inter-individual differences in drug disposition cannot be explained satisfactorily by factors such as a renal and/or liver function, patients' age and co-morbidity, life style, or patients' co-medication and compliance [1]. Therefore, genetic variations in the regulation, expression and activity of genes coding for Phase I, Phase II drug metabolizing enzymes (DMEs), drug targets and drug transporters, can be important determinants for drug efficacy and toxicity.

The growing body of consistent, reproducible findings for an increasing number of genetic markers for drug effectiveness and adverse drug reactions has resulted in an increasing number of pharmacogenetic effects being included in drug labels. Of the Food and Drug Administration (FDA) approved drug labels referring to human genomic biomarkers, $62.0 \%$ pertain 
to the above discussed polymorphisms in the $C Y P$ enzymes, with CYP2D6 (35.0\%; risperidone, tamoxifen, codeine, clozapine, metoprolol, etc.), CYP2C19 (17.0\%; clopidogrel, voriconazole, omeprazole), and CYP2C9 (7.0\%; celecoxib, warfarin) being the most common, as well as to polymorphisms in UGT1A1 (irinotecan, nilotinib) and $V K O R C l$ (warfarin) genes. The European Medicine Agency (EMA) also has a significant role in the implementation of the pharmacogenetic evidence in drug development, emphasizing the pharmacogenetic considerations and requirements for the pharmacokinetic characterization of medicinal products as a crucial step in designing and conducting drug development and drug evaluation investigations.

Besides the recognized inter-individual difference in drug response, the sequencing of the human genome has renewed and strengthened the interest in biological differences between racial and ethnic populations, as genetic variants associated with disease susceptibility, environmental response, and drug metabolism are identified, and frequencies of these variants in different populations are reported [2]. The availability of data from various genome re-sequencing projects has shown that the largest part of genetic variability within the human population is due to differences in individuals within populations, rather than to differences between populations [3]. A recent study, examining the global patterns of genetic diversity and signals of natural selection for human genes in 283 DMEs across 62 worldwide ethnic groups, suggests that genetic variants in absorption, distribution metabolism and elimination (ADME) genes could contribute to the intra-population heterogeneity in drug response [4].

The most prevalent allelic variants in three broad gene categories: the Phase I oxidation, cytochrome P450 (CYP450) family (CYP2D6, CYP2C19, CYP2C9, CYP3A5), the Phase II conjugation (GSTT1, SULT1A1, UGT1A1) and drug target (TYMS-TSER, $M T H F R$ and $V K O R C 1$ ). Their function, resulting enzyme activity and global frequencies in the European population have been extensively studied.

In the present study, our objective was to summarize the current knowledge about the frequency distribution of these genetic variants in the population of the Republic of Macedonia (Supplementary materials and methods), resulting from ongoing studies (unpublished data) as well as from studies already published, and compare the information received with data reported for other populations of European origin. We emphasize that the genetic variants presented and analyzed in this study are only the described ones, not all from Phase I, Phase II and drug target genes.

\section{GENETIC VARIANTS ASSOCIATED WITH A VARIABLE DRUG RESPONSE}

Phase I: Oxidation, CYP450 Family (CYP2D6, CYP2C19, CYP2C9, CYP3A5). The CYP450 isoform activity has emerged as a major determinant of the variability in drug metabolism and response as these enzymes are responsible for about $80.0 \%$ of all Phase I DMEs. Despite the large number of $C Y P$ genes and enzymes, 57 individual $C Y P$ genes organized in 18 gene families comprising 44 subfamilies, only the members of the CYP 2 and $C Y P 3$ gene families have a significant importance since they contribute to the metabolism of the majority of clinically important drugs $[5,6]$. The CYP2D6 enzyme, al-though expressed at low levels, constituting only $4.0-6.0 \%$ of the $C Y P$ content in the liver, metabolizes 25.0 to $30.0 \%$ of all clinically used drugs including anti-arithmics, antidepressants, anti-psychotics, beta blockers and codeine. The enzyme is the only one among the CYPs DMEs that is not inducible, and therefore, the genetic variation contributes largely to the inter-individual variation in the enzyme activity [7].

The CYP2C19 enzyme plays a critical role in the oxidative biotransformation of approximately $10.0 \%$ of the commonly used drugs belonging to drug classes such as proton pump inhibitors, tricyclic anti-depressants, selective serotonin reuptake inhibitors, benzodiazepines, barbiturates, phenytoin, voriconazole, nelfinavir and proguanil [7,8], whereas, the $C Y P 2 C 9$ enzyme contributes to the metabolism of $15.0 \%$ of clinically important drug classes, such as nonsteroidal anti-inflamatory drugs, angiotensin II receptor antagonist, anti-diabetic drugs, diuretic torsemide as well as the narrow therapeutic index drugs such as phenytoin and warfarin [7,9]. The CYP3A enzymes are responsible for the metabolism of approximately $50.0 \%$ of the currently marketed drugs, including steroids, anti-depressants, immunosuppressive agents and anti-biotics. The CYP $3 A 5$ is the primary extrahepatic $C Y P 3 A$ isoform, and typically, displays decreased catalytic activity compared to $C Y P 3 A 4[5,9]$. The CYP450 allelic variant and numerous subvariants 
reported to date are summarized at the Human CYP Allele Nomenclature Committee website (http:// www. cypalleles.ki.se/).

Currently, over 100 allelic variants and numerous subvariants have been identified within the CYP2D6 gene. The most important non functional alleles that are predominantly responsible for poor metabolizers (PMs) and account for $90.0-95.0 \%$ of PMs in indigenous Europeans are $C Y P 2 D 6^{*} 3, C Y P 2 D 6^{*} 4$ and $C Y P 2 D 6 * 6[10]$. The $C Y P 2 D 6 * 4$ with an allele frequency of $12.0-21.0 \%$, is the most common allele associated with PMs. Other detrimental alleles, $C Y P 2 D 6^{*} 3$ and $C Y P 2 D 6^{*} 6$, are frequently found in indigenous Europeans (1.0-2.0\%), but are very rare or absent in other populations. The most common alleles with severely reduced activity are represented by $C Y P 2 D 6^{*} 9, C Y P 2 D 6^{*} 10, C Y P 2 D 6^{*} 17$ and $C Y P 2 D 6 * 41$. The frequency of CYP2D6 deletions ranges from $2.0-7.0 \%$ in indigenous Europeans, $6.0 \%$ in Blacks and less than 1.0\% in Asians and 2.0-10.0\% of the populations carry multiple copies of the functional CYP2D6 allele [7,11].

The majority of PMs of $C Y P 2 C 19$ are due to the CYP2C19*2 (681G $>A)$ and $C Y P 2 C 19 * 3(636 \mathrm{G}>\mathrm{A})$ allelic variants that are non functional alleles, resulting in a complete loss of enzyme activity. They account for $95.0 \%$ of PMs. The frequency of the CYP $2 C 19 * 2$ allele ranges between 15.0-17.0\% in indigenous Europeans and Blacks and up to $30.0 \%$ in the Asian population. The most common allele associated with ultrarapid enzyme activity, $C Y P 2 C 19 * 17(-806 \mathrm{C}>\mathrm{T})$, has a similar allelic frequency of $15.0-25.0 \%$ in both the indigenous European and Black populations, and much reduced frequency (4.0\%) in Asians [7,12].

The most prevalent CYP2C9 alleles in the European population are $C Y P 2 C 9 * 2(430 \mathrm{C}>\mathrm{T})$ and CYP2C9*3 $(1075 \mathrm{~A}>\mathrm{T})$. Both are decreased-function alleles, lead to significant reduction in the enzymatic activity of the CYP2C 9 enzyme and account for $85.0 \%$ of PM phenotypes. The reported frequencies of $C Y$ $P 2 C 9 * 2$ and $C Y P 2 C 9 * 3$, ranges between $13.0-22.0 \%$ and $4.0-6.0 \%$, respectively, in indigenous Europeans, but are much lower in Blacks and Asians $[7,9,12]$.

CYP $3 A 5$ is a highly polymorphic enzyme as a result of mutations that severely diminish the synthesis of the functional $C Y P 3 A 5$ protein. The $C Y P 3 A 5 * 3 C$ $(6986 \mathrm{~A}>\mathrm{G})$ mutant is the major defective allele, leading to alternative splicing and protein truncation, which in turn results in the absence of the enzyme activity. It is widely detectable in the indigenous European population $(85.0-98.0 \%)$ with a lower frequency in the Black (27.0-48.0\%) and Asian (60.0-75.0\%) populations $[7,12,13]$.

Distribution of the CYP450 (CYP2D6, CYP2C19, CYP2C9, CYP3A5) Genetic Variants in the Population of the Republic of Macedonia. The allelic and genotype frequency distributions in our population and the correlated CYP450 phenotype status for the investigated DMEs are presented in Table 1. The CYP2D6 gene is considered a challenge for genotyping because its genetic variants include not only single nucleotide polymorphisms (SNPs), but copy number variations (CNVs) as well. The optimum amount of genotyping required to accurately predict the CYP2D6 phenotype remains debatable. A total of 11 different CYP2D6 variant alleles have been identified in our population. The prevalence of both inactive $(* 3, * 4$ and $* 6)$ and decreased activity )*9, $* 10$ and $* 41$ ) alleles was estimated to be 0.324 . The most frequently observed variant allele was $* 4$, accounting for 0.575 of all variant alleles. A total of 33 different genotypes were identified. The geno-typephenotype association was made according to the CYP2D 6 DPWG Genotype Phenotype Classification System (http://www.pharmgkb.org). Table 2 summarizes the resulting CYP2D6 genotypes and corresponding phenotypes recognized in the population of the Republic of Macedonia. Our results regarding the CYP2D6 profile were generally in accordance with the frequencies reported for other European populations (Supplementary Table 1A; references 5-18). Statistically significant differences were found in comparison to the prevalence of the CYP2D6 gene duplication and deletion. We report a higher frequency of CYP2D6 duplications/deletions in the Republic of Macedonia compared to that of Germany, France, Russia and Croatia $[5,14,17]$. These findings regarding the distribution of the CYP2D6 CNV status corresponds to the north-south gradient theory, suggesting a decreasing prevalence of CYP2D6 CNV from the Mediterranean countries towards Northern Europe. The frequency distribution of CYP2D6 PMs is similar to that of the other European populations [10,11,15-23].

All six possible $C Y P 2 C 19 * 2$ and $* 17$ genotypes with the corresponding phenotypes $\left[{ }^{*} 1 /{ }^{*} 1\right.$ and $* 1 / * 2$, both specifying extensive metabolizers (EMs); $* 1 / * 17$ and $* 17 / * 17$ indicative for ultrarapid metabolizers (UMs); *2/*2 predicting PM and the $* 2 / * 17$ com- 
Table 1. Allelic frequencies and genotype/phenotype distributions of the evaluated Phase I-oxidation, CYP450 genetic variants in the healthy population of the Republic of Macedonia.

\begin{tabular}{|c|c|c|c|c|c|c|}
\hline Gene & $n$ & Variant Alleles ${ }^{\mathrm{a}}$ & Frequency & $\begin{array}{c}\text { Genotype } \\
\text { (phenotype) }\end{array}$ & Frequency & References \\
\hline CYP2D6 & 184 & $\begin{array}{c}* 1^{\mathrm{b}} \\
* 2 \\
* 3 \\
* 4 \\
* 6 \\
* 9 \\
* 10 \\
* 41 \\
* 33 \\
* 35 \\
* 34 \\
* 39 \\
\\
\mathrm{~N}>2 \text { (duplication) } \\
\mathrm{N}<2 \text { (deletion) }\end{array}$ & $\begin{array}{l}0.249 \\
0.108 \\
0.008 \\
0.187 \\
\\
0.000 \\
0.016 \\
0.027 \\
0.086 \\
0.019 \\
0.100 \\
0.054 \\
0.146 \\
\\
0.059 \\
0.091\end{array}$ & $\begin{array}{l}\mathrm{EM}^{\mathrm{c}, \mathrm{d}} \\
\mathrm{IM}^{\mathrm{e}, \mathrm{r}} \\
\\
\mathrm{PM}^{\mathrm{g}} \\
\mathrm{UM}^{\mathrm{h}}\end{array}$ & $\begin{array}{l}0.320 \\
0.054 \\
0.043\end{array}$ & this study \\
\hline СYР2C19 & 184 & $\begin{array}{l}* 1^{\mathrm{b}} \\
* 2 \\
* 17\end{array}$ & $\begin{array}{l}0.654 \\
0.144 \\
0.202\end{array}$ & $\begin{array}{c}* 1 / * 1(\mathrm{IM}) \\
* 1 / * 2(\mathrm{IM}) \\
* 2 / * 2(\mathrm{PM}) \\
* 2 / * 17(\text { difficult to predict) } \\
* 17 / * 17(\mathrm{UM}) \\
* 1 / * 17(\mathrm{UM})\end{array}$ & $\begin{array}{l}0.418 \\
0.190 \\
0.027 \\
0.043 \\
0.038 \\
0.283\end{array}$ & 23 \\
\hline СУР2C9 & 179 & $\begin{array}{l}* 1 \text { b } \\
* 2 \\
* 3\end{array}$ & $\begin{array}{l}0.788 \\
0.139 \\
0.073\end{array}$ & $\begin{array}{l}* 1 / * 1(\mathrm{EM}) \\
* 1 / * 2(\mathrm{IM}) \\
* 2 / * 2(\mathrm{PM}) \\
* 2 / * 3(\mathrm{PM}) \\
* 3 / * 3(\mathrm{PM}) \\
* 1 / * 3(\mathrm{IM})\end{array}$ & $\begin{array}{l}0.610 \\
0.210 \\
0.027 \\
0.010 \\
0.010 \\
0.110\end{array}$ & 23 \\
\hline CYP $3 A 5$ & 174 & $\begin{array}{l}* 1^{\mathrm{b}} \\
* 3\end{array}$ & $\begin{array}{l}0.092 \\
0.908\end{array}$ & $\begin{array}{l}* 1 / * 1(\mathrm{EM}) \\
* 1 / * 3(\mathrm{IM}) \\
* 3 / * 3(\mathrm{PM})\end{array}$ & $\begin{array}{l}0.011 \\
0.160 \\
0.827\end{array}$ & 25 \\
\hline
\end{tabular}

EM: extensive metabolizers; IM: intermediate metabolizers; PM: poor metabolizers; UM: ultrarapid metabolizers.

${ }^{a}$ Labeling and terminology according to DPWG genotype-Phenotype table (http://www.pharmgkb.org).

${ }^{\mathrm{b}}$ Defined by the absence of variant alleles.

${ }^{\mathrm{c}}$ Carrier of two active alleles.

${ }^{\mathrm{d}}$ Carrier of one active and one decreased-activity allele.

${ }^{\mathrm{e}}$ Carrier of two decreased-activity alleles.

${ }^{\mathrm{f}}$ Carrier of one inactive and one decrease or active allele.

${ }^{\mathrm{g}}$ Carrier of two inactive alleles.

${ }^{\mathrm{h}}$ Carrier of $\mathrm{CNV}, \mathrm{N}>2$.

bined heterozygous genotype with a difficult to predict phenotype] have been identified [23] (Table 1). The detected frequency of the most common CYP2C19 variant alleles in the population of the Republic of Macedonia is within the range comparable with other European populations (Supplementary Table 1A; references 7,11-14,18-36). According to the previously reported data [24], the $C Y P 2 C 19 * 3$ allele has a very rare occurrence in the population of the Republic of Macedonia and therefore, it was not a subject of comparison in this study.

The allelic frequencies for $C Y P 2 C 9 * 2$ and $C Y$ $P 2 C 9 * 3$ found in our population correspond to the general frequencies reported for the various ethnic groups throughout Europe (Supplementary Table 1B; references 11-14,20,23, 34-47). The frequencies of the 
CYP2C9 genotypes associated with PM phenotypes $(0.297), * 2 / * 2$ and $* 3 / * 3$ were found to be 0.026 and 0.010 [23], respectively (Table 1 ).

The $C Y P 3 A 5 * 3$ allele was abundantly present in the specimens of our study with a frequency of 0.908 . We found no statistically significant difference compared to the frequencies reported for other Europeans (Supplementary Table 1B; references 13,36,48-52). Since heterozygotes and wild types for $C Y P 3 A 5 * 3$ may have a $C Y P 3 A 5$ activity, we estimate that 0.82 of the population of the Republic of Macedonia do not have a CYP $3 A 5$ enzymatic activity [25]. This is in agreement with the finding that $10.0 \%$ of the indigenous European population are high expressers of $C Y P 3 A$ [13].

Phase II: Conjugation (GSTT1, SULT1A1; UGT1A1). Extensive polymorphism also occurs in the majority of Phase II drug metabolizing enzymes. Sulfo-transferases and UDP-glucuronosyltransferases are two important phase II enzyme families that catalyze the sulfate and glucuronide conjugation of many endogenous and exogenous substances. The most frequent polymorphism in the SULTIA1 gene is the $S U L T 1 A 1 * 2(638 \mathrm{G}>\mathrm{A})$ that is correlated with a diminished capacity to sulphate $S U L T 1 A 1$ substrates. The greatest clinical significance of SULTIA1 is its role in the metabolism of estrogens and tamoxifen [26]. UGT1A1 pharmacogenetics has been studied more extensively than that of other uridine 5 '-diphospho-glucuronosyltransferases (UGTs). The greatest clinical significance has the $U G T 1 A 1 * 28$ variant allele correlated with an altered level of the enzyme expression and therefore a low enzymatic activity. It has been associated with adverse drug reactions (ADRs) due to reduced clearance, most notably lifethreatening toxicity of chemotherapy with a high-dose irinotecan [27].

Ethnic variations in allele frequencies observed for SULT1A1*2 ranges from 0.332 in indigenous Europeans, 0.080 in Asians and 0.294 in AfricanAmericans. The frequency of the UGT1A1*28 allele varies among ethnicities, being the highest in those of African (43.0\%) or European (39.0\%) descent and the lowest in those of Asian (16.0\%) descent [26,27].

Glutathione S-transferases (GSTs), are active in the detoxification of a wide variety of potentially toxic and carcinogenic electrophiles in conjugation with glutathione (GSH). The most common polymorphism is caused by a gene deletion that results in the absence of GSTT1 enzyme activity and has been associated
Table 2. Predicted phenotypes from the CYP2D6 genotype and genotype frequencies in a sample from the population of the Republic of Macedonia $(\mathrm{n}=184)$.

\begin{tabular}{|c|c|c|}
\hline $\begin{array}{c}\text { Predicted } \\
\text { Phenotype }^{\mathrm{a}}\end{array}$ & $\begin{array}{c}\text { Genotype }{ }^{\mathrm{a}} \\
(n)\end{array}$ & $\begin{array}{l}\text { Observed } \\
\text { Frequency }\end{array}$ \\
\hline EM & $\begin{array}{c}\text { Normal/Normal (87) } \\
* 1 / * 1 \\
* 1 / * 2 \\
* 1 / * 35 \\
* 2 / * 2 \\
* 34 / * 34 \\
* 39 / * 39 \\
* 2 / * 33 \\
* 2 / * 35 \\
* 34 / * 35 \\
* 35 / * 35 \\
* 39 / * 39-* 33 / * 33\end{array}$ & $\begin{array}{l}0.028 \\
0.262 \\
0.112 \\
0.009 \\
0.047 \\
0.243 \\
0.028 \\
0.019 \\
0.047 \\
0.009 \\
0.009\end{array}$ \\
\hline EM & $\begin{array}{c}\text { Normal/Decreased (18) } \\
* 1 / * 10 \\
* 1 / * 41 \\
* 35 / * 10 \\
* 2 / * 9 \\
* 35 / * 41 \\
* 35-* 41 / * 41 \\
* 2 / * 4 / * 35\end{array}$ & $\begin{array}{l}0.028 \\
0.047 \\
0.028 \\
0.009 \\
0.037 \\
0.009 \\
0.009\end{array}$ \\
\hline EM & $\begin{array}{c}\text { Normal/Inactive, } \\
\text { Duplication }(2) \\
* 35 / * 4 \mathrm{~N} \\
* 1 / * 4 \mathrm{~N}\end{array}$ & $\begin{array}{l}0.009 \\
0.009\end{array}$ \\
\hline IM & $\begin{array}{c}\text { Normal/Inactive }(41) \\
\quad * 1 / * 4 \\
* 2 / * 3 \\
* 35 / * 3 \\
* 35 / * 4 \\
* 33 / * 4 \\
\end{array}$ & $\begin{array}{l}0.576 \\
0.017 \\
0.034 \\
0.034 \\
0.034\end{array}$ \\
\hline IM & $\begin{array}{c}\text { Decreased/Decreased (10) } \\
\quad * 9 / * 10 \\
\quad * 10 / * 10 \\
* 10 / * 41 \\
* 41 / * 41\end{array}$ & $\begin{array}{l}0.017 \\
0.017 \\
0.017 \\
0.119\end{array}$ \\
\hline IM & $\begin{array}{c}\text { Decreased/Inactive }(8) \\
* 9 / * 4 \\
* 41 / * 4 \\
* 41 / * 41-4(\text { score }=1)\end{array}$ & $\begin{array}{l}0.068 \\
0.051 \\
0.017\end{array}$ \\
\hline PM & $\begin{array}{c}\text { Inactive/Inactive (10) } \\
* 4 / * 4\end{array}$ & 1.000 \\
\hline UM & $\begin{array}{c}\text { Normal/Normal, } \\
\text { Duplication }(8) \\
* 1 / * 2 \\
\quad * 1 / * 41 \\
\quad * 34 / * 35 \\
* 35 / * 35 \\
* 34 / * 34 \\
\quad * 39 / * 39\end{array}$ & $\begin{array}{l}0.250 \\
0.125 \\
0.125 \\
0.125 \\
0.250 \\
0.125\end{array}$ \\
\hline
\end{tabular}

a Labeling and terminology according to DPWG Geno-typePhenotype table (http://www.pharmgkb.org). 
Table 3. Allelic frequencies and genotype/phenotype distributions of the evaluated Phase II: conjugation of genetic variants in the healthy population of the Republic of Macedonia.

\begin{tabular}{|c|c|c|c|c|c|c|}
\hline Gene & Individuals & Variant Alleles & Frequency & Genotype & Frequency & References \\
\hline \multirow{2}{*}{ SULT1A1 } & \multirow{2}{*}{200} & $* 1(638 \mathrm{G})$ & 0.633 & $\mathrm{GG}$ & 0.435 & 29 \\
& & $* 2(638 \mathrm{~A})$ & 0.367 & $\mathrm{GA}$ & 0.395 & 0.17 \\
\hline \multirow{2}{*}{ UGT1A1 } & \multirow{2}{*}{96} & $* 1(\mathrm{TA} 6)$ & 0.690 & $* 1 / * 1$ & 0.500 & 30 \\
& & $* 28(\mathrm{TA} 7)$ & 0.310 & $* 28 / * 28$ & 0.125 & no null \\
\hline \multirow{2}{*}{ GSTT1 } & \multirow{2}{*}{128} & & & null & 0.870 & this study \\
\hline
\end{tabular}

with a reduction of the relapse risk in several tumor types (acute lymphoblastic leukemia, acute myeloblastic leukemia, breast cancer, ovarian cancer and lung cancer) treated with chemotherapy. Reported frequencies for the GSTT1 null genotype from different ethnic groups show a range of $16.0-60.0 \%$ for Asians, $15.0-26.0 \%$ for Africans and 10.0-20.0\% for the European population $[26,28]$.

Distribution of the Phase II Conjugation (GSTT1, SULT1A1; UGT1A1) Genetic Variants in the Population of the Republic of Macedonia. For the SULT1A1 (638G>A) polymorphism, approximately one-third of the population from the Republic of Macedonia carry the low-activity SULT1A1 *2 allele and $17.0 \%$ are predicted to be homozygous for the SULT1A1*2 genetic variant [29] (Table 3). The distributions of the UDP-glucuronosyltransferase (UGT) $1 A 1 * 28$ allele and genotype frequencies in our population are summarized in Table 3 [30]. Regarding the GSTT1 genotype distribution, $16(0.13)$ out of 128 study subjects were predicted to carry the null genotype.

We found no significant difference in SULT1A1*2 allelic and genotype distribution in our population compared to the one reported for other Europeans (Supplementary Table 2; references 53-57). Our findings regarding allelic and genotypic frequencies for $U G T 1 A 1 * 28$ genetic variant are comparable to those observed in the Framingham Heart Study that comprises subjects of almost entirely European descent from England, Ireland, France and Italy, and to the variant allele frequency reported for the Turkish population (Supplementary Table 2; references 58-63). The results concerning the population frequency of GSTT1 null genotypes corroborate the regional frequency gradients of the GSTT1 null allele that exist within the European populations (Supplementary Table 2; references 18, 64-70).

Drug Target Genetic Variants (MTHFR, TYMS-TSER, VKORC1). Polymorphisms in drug targets are also an important area for pharmacogenetic studies, since an over-expression or under-expression of drug targets could also lead to resistance or toxicity in standard chemotherapy regimens. Two polymorphisms of folate cycle enzymes, methylenetetrahydrofolate reductase (MTHFR) C677T and thymidylate synthase (TYMS) enhancer region (TSER) 28 bp tandem repeat, are the two most important intracellular targets for several chemotherapeutic drugs, including antifolates (metotrexate) and fluoropirimidines (5FU, capecitabine), respectively [31]. The most common MTHFR $677 C>T$ variant is associated with a decreased enzyme activity and increased metotrexate intolerance. The polymorphism of a $28 \mathrm{bp}$ sequence in the 5 ' promoter enhancer region of the TS gene (TSER) varies from two $(T S E R * 2)$ to nine $(T S E R * 9)$ copies of the tandem repeat, with TSER $* 2$ and TSER $* 3$ being the most common alleles. The second SNP within the second repeat of TSER*3 (TSER*3RG $>C$ ), upregulates the $T S$ expression and is associated with resistance to TS-targeted chemotherapy. The MTHFR C677T polymorphism shows wide regional and ethnic variations among the European population (23.0$41.0 \%$ ), Asian countries (40.0-44.0\%) and Africans $(12.0,6.0 \%)$ [31,32]. Inter-population differences have also been documented for TYMS-TSER genetic variants; the frequencies reported for TSER $* 3$ allele within the Asian, indigenous European and African populations were $0.81,0.60$ and 0.52 , respectively [32,33]. 
Table 4. Allelic frequencies and genotype distributions of the evaluated drug target genetic variants in the healthy population of the Republic of Macedonia.

\begin{tabular}{|c|c|c|c|c|c|c|}
\hline Gene & Individuals & Variant Alleles & Frequency & Genotype & Frequency & References \\
\hline MTHFR & 185 & $\begin{array}{l}677 \mathrm{C} \\
677 \mathrm{~T}\end{array}$ & $\begin{array}{l}0.586 \\
0.414\end{array}$ & $\begin{array}{l}\text { CC } \\
\text { CT } \\
\text { TT }\end{array}$ & $\begin{array}{l}0.350 \\
0.470 \\
0.180\end{array}$ & 35 \\
\hline TYMS-TSER & 105 & $\begin{array}{l}2 \mathrm{R} \\
3 \mathrm{C} \\
3 \mathrm{G}\end{array}$ & $\begin{array}{l}0.376 \\
0.395 \\
0.228\end{array}$ & $\begin{array}{l}2 \mathrm{R} / 2 \mathrm{R} \\
2 \mathrm{R} / 3 \mathrm{C} \\
2 \mathrm{R} / 3 \mathrm{G} \\
3 \mathrm{C} / 3 \mathrm{C} \\
3 \mathrm{C} / 3 \mathrm{G}\end{array}$ & $\begin{array}{l}0.120 \\
0.300 \\
0.200 \\
0.190 \\
0.100\end{array}$ & 36 \\
\hline VKORC1 & 101 & $\begin{array}{l}-1639 \mathrm{G} \\
-1639 \mathrm{~A}\end{array}$ & $\begin{array}{l}0.624 \\
0.376\end{array}$ & $\begin{array}{l}\text { GG } \\
\text { GA } \\
\text { AA }\end{array}$ & $\begin{array}{l}0.396 \\
0.455 \\
0.149\end{array}$ & this study \\
\hline
\end{tabular}

The VKORC1 gene encodes for the enzyme vitamin $\mathrm{K}$ epoxide reductase that is the pharmacodynamic target of coumarinic oral anticoagulants. The VKORC1 (-1639 $G>A)$ variant, the one SNP included in the International Warfarin Pharmacogenetics Consortium (IWPC) dosing algorithm, has been shown to confer a high risk of bleeding, predisposing the individuals carrying these polymorphisms to hemorrhagic incidents. In general, the A allele has an increasing frequency from Western Europe (40.0\%) towards Eastern Asia (90.0\%) [34].

Distribution of the Drug Target Genetic Variants in the Population of the Republic of Macedonia. The allelic frequencies and the genotype distributions of the MTHFR 677C $>T$ [35], TYMS-TSER $* 2 / * 3(2 \mathrm{R} / 3 \mathrm{R} ; 3 \mathrm{C} / 3 \mathrm{G})[36]$ and $V K O R C 1-1639 G>A$ genetic variants in our population are presented in Table 4. Both MTHFR C677T and TYMS-TSER genetic variants show wide regional and ethnic variations among the European population (Supplementary Table 2; references 71-90). Significantly higher frequencies of the MTHFR $677 T$ allele was observed when compared to the frequencies reported in the populations of the Nordic countries, Turkey and Croatia. There are few population studies of the TYMS-TSER locus in the literature and the frequencies reported for the TSER*3 allele correspond to that found in our population (Supplementary Table 2; references 80-90). The prevalence of $V K O R C 1-1639 G>A$ in the population of the Republic of Macedonia is in accordance with the values reported for other European populations (Supplementary Table 2; references 42,91-94).

\section{CONCLUSIONS}

Different populations or ethnic groups are likely to be more similar than different to each other. However, inter-individual differences in drug responses are well recognized and may be due to genetic or environmental influences. These contributing factors may also result in inter-ethnic or inter-geographic differences in drug response.

In addition, regional differences in the frequency of CYP 450 genetic variants leading to population specific DME activity patterns have been observed. Altogether, at least 28 out of 42 DMEs show differences between ethnically defined populations [12]. Several lines of evidence imply that the effect of demography on pharmacogenetic variations should be considered even on a microgeographic scale, especially when population sizes are small [5]. Thus, information regarding geographic structure and multi-ethnic distribution of clinically relevant genetic variations is becoming increasingly useful for improving drug therapy and explaining inter-individual and interethnic differences in drug response [4,5].

Given the recognized ethnic differences in drug responses and the fact that many genetic polymorphisms differ in frequency on the basis of ethnicity/ ancestry [7], it is not surprising that the inter-ethnic comparisons of drug response have become a major aspect of pharmacogenetics. Furthermore, the experts advise a careful consideration of the appropriate usage of drugs in populations where known ethnic differences occur and where genetic determinants may or may not be elucidated. Most of the European ethnic 
groups have already reported the frequency of the above mentioned genetic polymorphisms, but data regarding the distribution in the normal population of the Republic of Macedonia are deficient.

This study is the first to have reviewed and summarized the current knowledge about the frequency distribution of the most common allelic variants in three broad gene categories: Phase I-oxidation, CYP450 family (CYP2C9, CYP2C19, CYP3A5, CYP2D6), Phase II conjugation (GSTT1, SULT1A1, UGT1A1) and drug target (TYMS-TSER, MTHFR and VKORC1) in a population of the Republic of Macedonia compared to those reported for European populations.

Our findings define the population of the Republic of Macedonia as an ethnic group with a highly polymorphic genetic profile. These results add to the evidence regarding the distribution of clinically important variant alleles in DME and drug target genes in populations with European ancestry. They may serve as a background for comparison with other population samples and could be included in case-control studies as a reference for Macedonian population.

Declaration of Interest. The authors report no conflicts of interest. The authors alone are responsible for the content and writing of this article.

\section{REFERENCES}

1. Ma Q, Lu AY. Pharmacogenetics, pharmacogenomics, and individualized medicine. Pharmacol Rev. 2011; 63(2): 437-459.

2. Foster MW, Sharp RR. Race, ethnicity, and genomics: Social classifications as proxies of biological heterogeneity. Genome Res. 2002; 12(6): 844-850.

3. Stranger BE, Stahl EA, Raj T. Progress and promise of genome-wide association studies for human complex trait genetics. Genetics. 2011; 187(2): 367-383.

4. Li J, Zhang L, Zhou H, Stoneking M, Tang K. Global patterns of genetic diversity and signals of natural selection for human ADME genes. Hum Mol Genet. 2011; 20(3): 528-540.

5. Sistonen J, Fuselli S, Palo JU, Chauhan N, Padh $\mathrm{H}$, Sajantila A. Pharmacogenetic variation at CYP2C9, CYP2C19, and CYP2D6 at global and microgeographic scale. Pharmacogenet Genomics. 2009; 19(2): 170-179.
6. Yang X, Zhang B, Molony C, Chudin E, Hao K, Zhu J, et al. Systematic genetic and genomic analysis of cytochrome $\mathrm{P} 450$ enzyme activities in human liver. Genome Res. 2010; 20(8): 1020-1036.

7. McGraw J, Waller D. Cytochrome P450 variations in different ethnic populations. Expert Opin Drug Metab Toxicol. 2012; 8(3): 371-382.

8. Sim SC, Kacevska M, Ingelman-Sundberg M. Pharmacogenomics of drug-metabolizing enzymes: A recent update on clinical implications and endogenous effects. Pharmacogenomics J. 2013; 13(1): 1-11.

9. Zhou SF, Liu JP, Chowbay B. Polymorphism of human cytochrome P450 enzymes and its clinical impact. Drug Metab Rev. 2009; 41(2): 89-295.

10. Rebsamen MC, Desmeules J, Daali Y, Chiappe A, Diemand A, Rey C, et al. The AmpliChip CYP450 test: Cytochrome P450 2D6 genotype assessment and phenotype prediction. Pharmacogenomics J. 2009; 9(1): 34-41.

11. Sistonen J, Sajantila A, Lao O, Corander J, Barbujani G, Fuselli S. CYP2D6 worldwide genetic variation shows high frequency of altered activity variants and no continental structure. Pharmacogenet Genomics. 2007; 17(2): 93-101.

12. Kalow W. Pharmacogenetics: A historical perspective. In: McLeod HL, DeVane CL, Haga SB, Johnson JA, Knoel DL, Kolesar JM, et al., Eds. Pharmacogenomics: Application to Patient Care, 2nd ed. Lenexa, KS: American College of Clinical Pharmacy. 2009: 22-31.

13. van Schaik RH, van der Heiden IP, van den Anker JN, Lindemans J. CYP3A5 variant allele frequencies in Dutch Caucasians. Clin Chem. 2002; 48(10): 1668-1671.

14. Aynacioglu AS, Sachse C, Bozkurt A, Kortunay $\mathrm{S}$, Nacak M, Schröder T, et al. Low frequency of defective alleles of cytochrome P450 enzymes 2C19 and 2D6 in the Turkish population. Clin Pharmacol Ther. 1999; 66(2): 185-192.

15. Buzková H, Pechandová K, Slanar O, Perlik F. Frequency of single nucleotide polymorphisms of CYP-2D6 in the Czech population. Cell Biochem Funct. 2008; 26(1): 76-81.

16. Qumsieh RY, Ali BR, Abdulrazzaq YM, Osman O, Akawi NA, Bastaki SM. Identification of new alleles and the determination of alleles and 
genotypes frequencies at the CYP2D6 gene in Emiratis. PLoS One. 2011; 6(12): e28943. doi: 10.1371/journal.pone.0028943.

17. Scordo MG, Caputi AP, D’Arrigo C, Fava G, Spina E. Allele and genotype frequencies of CYP2C9, CYP2C19 and CYP2D6 in an Italian population. Pharmacol Res. 2004; 50(2): 195-200.

18. Bozina N, Granić P, Lalić Z, Tramisak I, Lovrić M, Stavljenić-Rukavina A. Genetic polymorphisms of cytochromes P450: CYP2C9, CYP2C19, and CYP2D6 in Croatian population. Croat Med J. 2003; 44(4): 425-428.

19. Arvanitidis K, Ragia G, Iordanidou M, Kyriaki $\mathrm{S}$, Xanthi A, Tavridou A, et al. Genetic polymorphisms of drug-metabolizing enzymes CYP2D6, CYP2C9, CYP2C19 and CYP3A5 in the Greek population. Fundam Clin Pharmacol. 2007; 21(4): 419-426.

20. Gaikovitch EA, Cascorbi I, Mrozikiewicz PM, Brockmöller J, Frötschl R, et al. Polymorphisms of drug-metabolizing enzymes CYP2C9, CYP2C19, CYP2D6, CYP1A1, NAT2 and of Pglycoprotein in a Russian population. Eur J Clin Pharmacol. 2003; 59(4): 303-312.

21. Yamada H, Dahl ML, Lannfelt L, Viitanen M, Winblad B, Sjoqvist F. CYP2D6 and CYP2C19 genotypes in an elderly Swedish population. Eur J Clin Pharmacol. 1998; 54(6): 479-481.

22. Falzoi M, Pira L, Lazzari P, Pani L. Analysis of CYP2D6 allele frequencies and identification of novel SNPs and sequence variations in Sardinians. ISRN Genet. 2013; 2013. Article ID 204560; http://dx.doi.org/10.5402/2013/204560.

23. Jakovski K, Kapedanovska Nestorovska A, Labacevski N, Dimovski AJ. Characterization of the most common CYP2C9 and CYP2C19 allelic variants in the population of R. Macedonia. Pharmazie. 2013; 68(11): 893-898.

24. Kapedanovska Nestorovska A, Cvetkovska Dimitrovska A, Suturkova Lj. Genetic profile of CYP2C19 polymorphisms in population from Republic of Macedonia. Macedonian Pharmaceutic Bull. 2011; 57(Suppl): 346-348.

25. Jakovski K, Kapedanovska Netorovska A, Labacevski N, Dimovski AJ. Frequency of most common CYP3A5 polymorphisms in the healthy population of the Republic of Macedonia. Macedonian Pharmaceutic Bull. 2012; 58(1-2): 25-31.
26. Hildebrandt MA, Carrington DP, Thomae BA, Eckloff BW, Schaid DJ, Yee VC, et al. Genetic diversity and function in the human cytosolic sulfotransferases. Pharmacogenomics J. 2007; 7(2): 133-143.

27. Horsfall LJ, Zeitlyn D, Tarekegn A, Bekele E, Thomas MG, Bradman N, et al. Prevalence of clinically relevant UGT1A alleles and haplotypes in African populations. Ann Hum Genet. 2011; 75(2): 236-246.

28. Polimanti R, Carboni C, Baesso I, Piacentini S, Iorio A, De Stefano GF, et al. Genetic variability of glutathione S-transferase enzymes in human populations: Functional inter-ethnic differences in detoxification systems. Gene. 2013; 512(1): 102-107.

29. Sterjev Z, Josifovski T, Panovski M, Sututkova L, Dimovski AJ. The SULT1A1 allele with low potential for estrogen inactivation is associated with reduced colorectal cancer risk in postmenopausal women. Balkan J Med Genet. 2005; 8(3-4): 43-48.

30. Bajro MH, Josifovski T, Panovski M, Jankulovski $\mathrm{N}$, Nestorovska AK, Matevska N, et al. Promoter length polymorphism in UGT1A1 and the risk of sporadic colorectal cancer. Cancer Genet. 2012; 205(4): 163-167.

31. Sharma R, Hoskins JM, Rivory LP, Zucknick M, London $\mathrm{R}$, Liddle $\mathrm{C}$, et al. Thymidylate synthase and methylenetetrahydrofolate reductase gene polymorphisms and toxicity to capecitabine in advanced colorectal cancer patients. Clin Cancer Res. 2008; 14(3): 817-825.

32. Wang H, Wang J, Zhao L, Liu X, Mi W. Methylenetetrahydrofolate reductase polymorphisms and risk of acute lymphoblastic leukemia-evidence from an updated meta-analysis including 35 studies. BMC Med Genet. 2012; 4: 13-77.

33. Acuña M, Eaton L, Cifuentes L, Massardo D. Genetic variants in the enhancer region of the thymidylate synthase gene in the Chilean population. Br J Clin Pharmacol. 2006; 61(6): 778-782.

34. Alzahrani AM, Ragia G, Hanieh H, Manolopoulos VG. Genotyping of CYP2C9 and VKORC1 in the Arabic Population of Al-Ahsa, Saudi Arabia. Biomed Res Int. 2013; 2013: 315980. doi: 10.1155/2013/3159980. 
35. Matevska N, Josifovski T, Kapedanovska A, Sterjev Z, Serafimoska Z, Panovski M, et al. Methylenetetrahydrofolate reductase C677T polymorphism and risk of colorectal cancer in the Macedonian population. Balkan J Med Genet. 2008; 11(2):17-24.
36. Kapedanovska Nestorovska A, Sterjev Z, Serafimoska Z, Josifovski T, Petrusevska N, Suturkova $\mathrm{L}$, et al. Thymidylate synthase enhancer region (TSER) 2R/3R polymorphisms as an independent risk factor for colorectal cancer in Macedonian population. Macedonian Pharmaceutic Bull. 2011; 57(Suppl): 348-349. 